\title{
Correspondence
}

\section{Mounting of the Bain circuit}

To the Editor:

We wish to describe a novel approach for the mounting of the Bain circuit. We are equipped with Drager Narkomed anaesthetic machines which incorporate a toggle switch governing circuit access to the breathing bag, or the ventilator. Unfortunately, the use of the Bain circuit on a standard mount precludes the use of this feature. Standard mounts also require a duplicate exhaust hose, and fittings for an oxygen sensor, resulting in a profusion of tubing, with considerable potential for error when

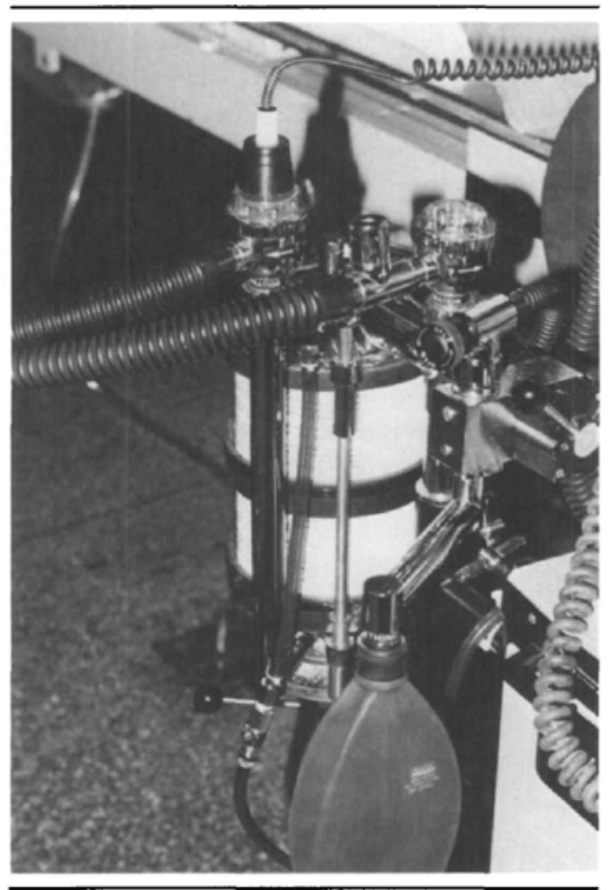

FIGURE 1a Drager Narkomed anaesthetic machine absorber with standard circle breathing system configuration. changing from the circle system to the Bain circuit.

For the past two years we have used a system in which the Bain circuit exhaust gas is collected by a "mini-circle" system mounted on the circle absorber (Figure 1). This enables us to use the Drager machine without further modification, and to eliminate duplicate exhaust and other connections. As well as simplifying changeover from one circuit to another, it obviates the need for an expensive Bain circuit mount, and, in our hands, has proven to be a very safe and utilitarian modification.

The problem of occluding the port for fresh gas flow into the circle absorber when delivering fresh gas to the Bain circuit was solved by our Respiratory Technology Department. Their solution to this problem has resulted in increased safety in

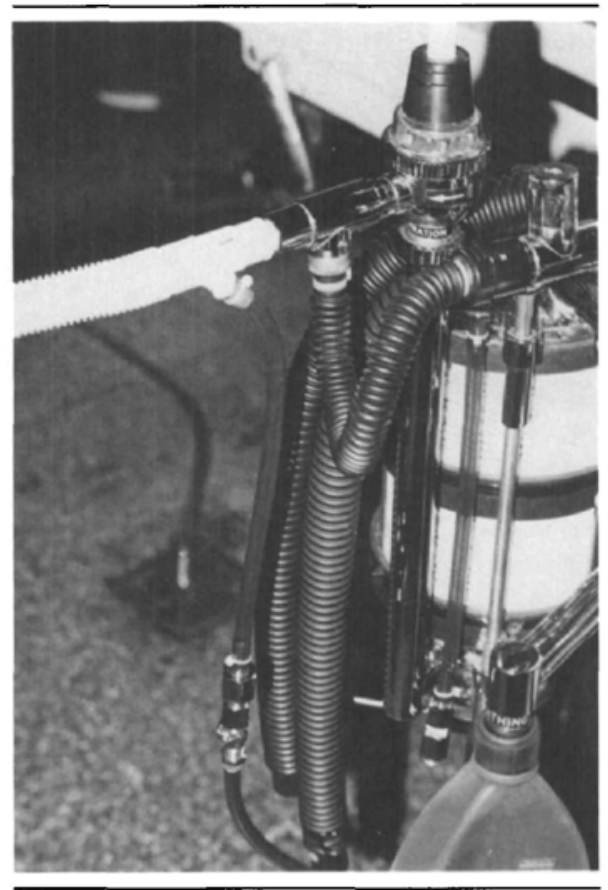

FIGURE lb Absorber with Bain circuit mounted using modification described in text. 


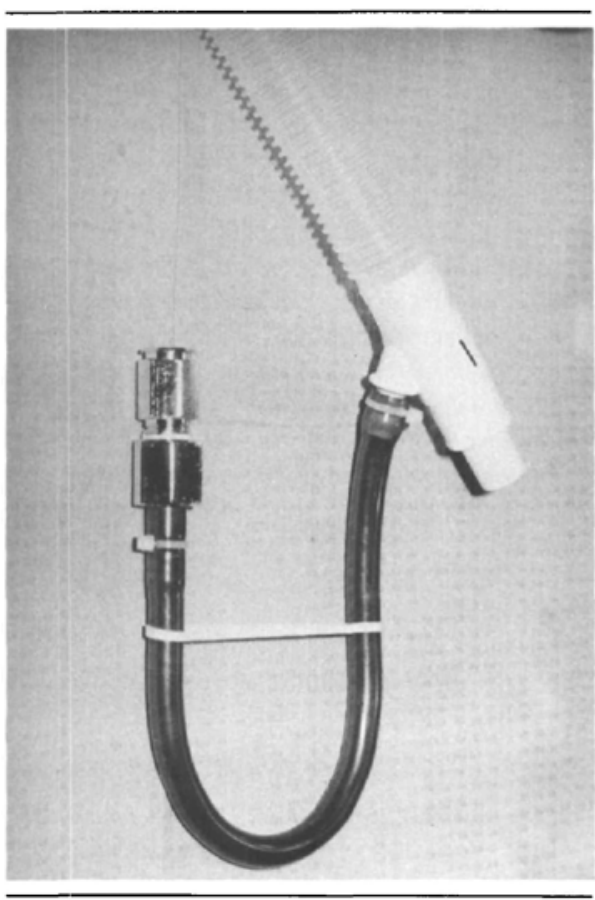

FIGURE 2 Proximal (machine) end of Bain circuit. Note special fresh gas tubing with attached female half of locking spring-loaded fitting. Male half of fitting is attached to tubing from common gas outlet of anaesthetic machine.

general, by virtually eliminating the hazard of disconnect at this point in the circuit. We use a locking spring-loaded fitting (ADEC Quick Disconnect-026-40 and 026-07), the fernale half of which is attached to the fresh gas inlet on the circle absorber, with a short length of tubing interposed for convenience. The male half of the fitting is attached to tubing from the fresh gas outlet on the machine body. When the male half of the fitting is withdrawn for use with the Bain circuit, a valve within the female half closes, preventing loss of gas from the circle absorber, and allowing the Bain circuit to be pressurized by the ventilator. Our Bain circuits (which we use for a week, pasteurizing during the course of this period and then discarding) are equipped with a short length of tubing swaged to the fresh gas inlet (Figure 2), with a duplicate female connector swaged onto the proximal end of this short length of tubing, mating with the male connector and tubing from the fresh gas outlet from the machine. We have removed the self-sealing valve from the female connectors on the Bain circuit to prevent the use of the circuit with the fresh gas flow still connected to the inlet on the circle absorber. We have found these connectors to be very positive and inherently foolproof.

Our system, of course, has maximum utility with the Drager machines, although I suspect other manufacturers will eventually provide the same capability of switching from breathing bag to ventilator and back again without disconnecting and reconnecting tubing.

We have one obvious caveat with respect to the mount, namely, in paediatric usage the resistance of the circle will be born by the smaller patient when breathing spontaneously. In our hands this has not proven to be a problem, since we are assisting or ventilating virtually all paediatric cases, and in fact inspiratory resistance is not a problem with the Bain, since fresh gas flow is delivered normally, and the expiratory resistance of the circle provides a $1-3 \mathrm{~cm} \mathrm{H}_{2} \mathrm{O}$ expiratory retard, which may very well be beneficial.

Unfortunately Drager machines do not incorporate a switch to exclude the absorber from the circle, which would result in further economy when using the Bain circuit, by preventing unwanted consumption of soda-lime. We suspect that the problem of soda-lime consumption is ameliorated by the high flow when using the Bain circuit, but have no data to support this assumption.

We hope that the inherent economy and versatility of this system will commend its use by others.

\section{R.N. Lyall MD FRCP}

L. Linder RRT

Royal Jubilee Hospital

Victoria, British Columbia

\section{COMMENT}

Thank you for the opportunity to comment on the modification reported by Lyall and Linder. We are impressed with the simplicity and ingenuity of this modification for use of the Bain circuit with the Drager anaesthetic machine.

An essential requirement of any modification to any piece of equipment which is directly concerned with patient care is to make sure it functions properly and can be effectively tested. All circuits and mounts must accommodate a pressure test for leaks $\left(30 \mathrm{~cm} \mathrm{H}_{2} \mathrm{O}\right)$ and 
the Pethick test (Can Anaesth Soc J 1975; 22: 115), to demonstrate the integrity of the fresh gas inflow line of the Bain circuit. This is particularly important when two breathing circuits which finction quite differenly share the same machine mount. Lyall and Linder assure us the connections they use are "positive and inherentiy foolproof."

The new mounting system appears eminently practical as it makes use of existing equipment. Although the soda-lime no longer has any function, its presence does no harm; the authors may find it possible to save the expense of the soda-lime as the use of the circle system declines. It should be noted that the Bain system and the circle system without soda-lime have very similar characteristics and could be used with the same fresh gas flows; however, for such use the fresh gas inflow port of the circle system would be better located on the inspiratory side.

The oxygen sensor, which monitors the inspired $\mathrm{O}_{2}$ in the circle system, now measures a mean expired axygen concentration in the reported modification. This could prove an equally valuable measurement, allowing in addition a rough estimate of the patient's $\mathrm{O}_{2}$ consumption (inspired per cent $\mathrm{O}_{2}-$ mean expired per cent $\mathrm{O}_{2} \times$ fresh gas flow).

The warning in regard to paediatric use because of an expiratory resistance of $1-3 \mathrm{~cm} \mathrm{H}_{2} \mathrm{O}$, should be noted. It is probably of little concern as most of our spring loaded pop-off valves have a resistance in the same order; we would have no cancern using this modification in small children.

W.E. Spoerel MD FRCP(C)

Department of Anacsthesia

University of Westem Ontario

J.A. Bain MD FRCP(C)

Department of Anaesthesia

Victoria Hospital

London, Ontario

\section{REFERENCE}

1 DeSilva AJC. Normocapnic yentilation using the circle system. Can Anaesth Soc J 1976; 23: $657-66$.

\section{Cardiovascular collapse associated with nitrous oxide administration}

To the Editor:

The case report of Davidson and Chinyanga ${ }^{1}$ of acute cardiovascular collapse following the administration of nitrous oxide in a child with pulmo- nary artery hypertension brings to fore the danger of nitrous oxide use in the patient with pulmonary artery hypertension. Lappas et al. ${ }^{2}$ and SchulteSasse et al. ${ }^{3}$ graphically demonstrated the effects of nitrous oxide on pulmonary artery pressure in patients undergoing cardiopulmonary bypass procedures. Despite the argument presented by Davidson and Chinyanga, the proximal pulmonary artery pressure in their patient was elevated and certainly could have increased markedly with the addition of the nitrous oxide, resulting in right ventricular failure and cardiac arrest.

I believe more thought should be given before nitrous oxide is used in any patient and particularly any infant who has an elevated pulmonary artery pressure

\section{James Mayhew MD}

Department of Anesthesiology

University of Texas Health Science Center

Houston, Texas

\section{REFERENCES}

1 Davidson JR, Chinyanga HM. Cardiovascular collapse associated with nitrous oxide anaesthetic: a case report. Can Anaesth Soc J 1982; 29: 484-8.

2 Lappas DG, Buckley MJ, Laver MB, Daggett $W M$ Lowenstein $E$. Left ventricular performance and pulmonary circulation following addition of nitrous oxide to morphine during coronary-artery surgery. Anesthesiology 1975; 43: 61-9.

3 Schulte-Sasse Y, Hess W, Tarnow J. Pulmonary vascular responses to nitrous oxide in patients with normal and high pulmonary vascular resistance. Anesthesiology 1982; 57: 9-13.

\section{REPLY}

While we noted the increased impedance to right ventricular output in our young parient, we were less convinced about the elevated pressure in the right pulmonary artery being reflected to the narrowed peripheral branches of both pulmonary arteries. Despite this, nitrous oxide was introduced cautiously $\left(\mathrm{N}_{2} \mathrm{O}_{1} \mathrm{O}_{2} \mathrm{FlO}_{3}=0.5\right)$. We completely agree with the firm warning of Dr. Mayhew on the administration of nitrous axide to very sick patients, particularly infants whose pulmonary artery pressure is elevated.

I now use isofurane in a mixture of air and oxygen for similar cases, with satisfying results.

Herbert M. Chinyanga MD FRCP(C)

Department of Anaesthesia

The Hospital for Sick Chidren

Toronto, Ontario 